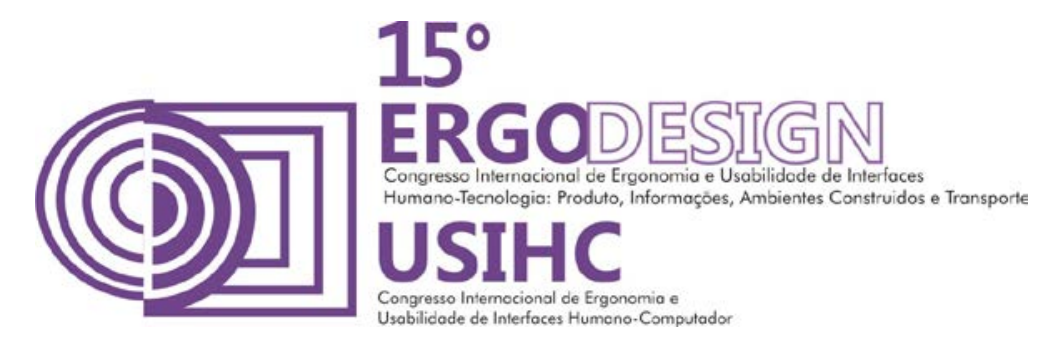

\title{
'VER COM AS MÃOS': A TECNOLOGIA 3D COMO RECURSO EDUCATIVO PARA PESSOAS CEGAS.
}

\author{
SOBRAL, João Eduardo Chagas (1) \\ CAVALCANTI, Anna Luiza Moraes de Sá (2) \\ EVERLING, Marli Teresinha (3)
}

(1) Universidade da Região de Joinville - Univille, Graduação

e-mail: sobral41@gmail.com

(2) Universidade da Região de Joinville - Univille, Mestre

e-mail: anacavalcanti08@gmail.com

(3) Universidade da Região de Joinville - Univille, Doutorado

e-mail: marli.everling@gmail.com

\begin{abstract}
RESUMO
HOMERO 3D é o grupo de grupo de estudos que visa fomentar a pesquisa e o desenvolvimento de projetos de design utilizando a tecnologia de impressão 3D como recurso educacional para pessoas cegas ou com baixa visão. Por meio deste artigo, discute-se as informações obtidas com o levantamento bibliográfico e o levantamento de projetos com objetivos similares compartilhados no espaço virtual. Os resultados obtidos nesta etapa fundamentarão as outras ações do grupo de estudos.
\end{abstract}

\begin{abstract}
HOMERO $3 D$ is the name of the team created to promote design research related to $3 D$ print technology as an educational resource. The aim of this paper is to discuss information obtained throughout the literary review and the analysis of similar projects shared in a virtual space. The results will be helpful to ground the next stages of the research.
\end{abstract}

\section{INTRODUÇÃO}

O grupo de estudos HOMERO 3D visa fomentar o debate, a discussão, a pesquisa e o desenvolvimento de projetos de design que exploram a tecnologia de impressão 3D como recurso educacional de pessoas cegas ou com baixa visão. O grupo está vinculado ao Projeto Estudo comparativo, dos métodos de fabricação digital e da produção de imagens fotográficas adstritas ao contexto do artefato tridimensional nas dimensões da concepção, desenvolvimento 


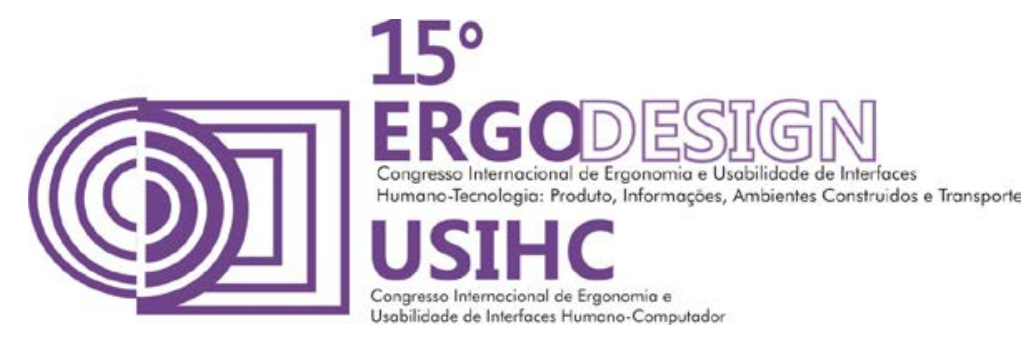

e do ensino e aprendizagem do design (financiado pelo Conselho Nacional de Desenvolvimento Científico e Tecnológico/CNPq).

Dentre as ações previstas pelo grupo constam: levantamento bibliográfico, criação de um espaço virtual para o compartilhamento de informações, abertura do grupo para organizações que atuem com indivíduos de baixa visão e pessoas cegas. Por meio deste artigo, apresenta-se as informações obtidas em levantamento bibliográfico e na análise de projetos com objetivos similares compartilhados no espaço virtual. Os resultados obtidos nesta etapa fundamentarão os outros estágios do grupo de estudos.

A estrutura que orientou a organização do artigo abrange: potencialidades e limites da impressão 3D, o sentido tátil e a educação para pessoas de baixa visão ou cegas, a tecnologia 3D e sua potencialidades como ferramenta de visualização e comunicação no processo educativo. A reflexão sobre as informações levantas está nas considerações finais.

\section{POTENCIALIDADES E OS LIMITES DA IMPRESSÃO 3D}

A democratização da tecnologia digital traz em sua esteira a reestruturação de aspectos da vida cotidiana. Se a tecnologia da informação e da comunicação contribui para a virtualização e desmaterialização de rotinas cotidianas antes apoiadas em artefatos físicos, a impressão 3D (também chamada de prototipagem rápida) abre outras possibilidades agora relacionadas a materialização de objetos.

Como toda a tecnologia em desenvolvimento ou consolidação, ela suscita debates éticos acerca da finalidade de seu uso: ela estará a serviço da vida (na área da saúde, educação e democratização de produtos considerados critérios mínimos para a qualidade de vida), ou pode ameaçá-la (reprodução de armas e outros artefatos)?

Criada na década de 80 (século XX) a impressão 3D (que também é chamada de prototipagem rápida) vem se popularizando nos mais diversos campos do conhecimento (design, saúde, indústria, arquitetura, alimentos) e com a redução de custos também está sendo utilizada em proposta 'faça você mesmo' (do it yourself/diy) e propostas artísticas como a exposição 3D: Printing The Future realizada em novembro de 2013 no Museu de Ciências de Londres $^{1}$. Acredita-se que em poucos anos a tecnologia será utilizada no cotidiano das pessoas ${ }^{2}$ o que possibilita também o seu uso como ferramenta que possibilita aos cegos 'ver com as mãos'.

\footnotetext{
${ }^{1}$ London Museum Uses Israeli Tech To Create 3d Printed Statues Of Visitors (web).

2 Duarte (web)
} 


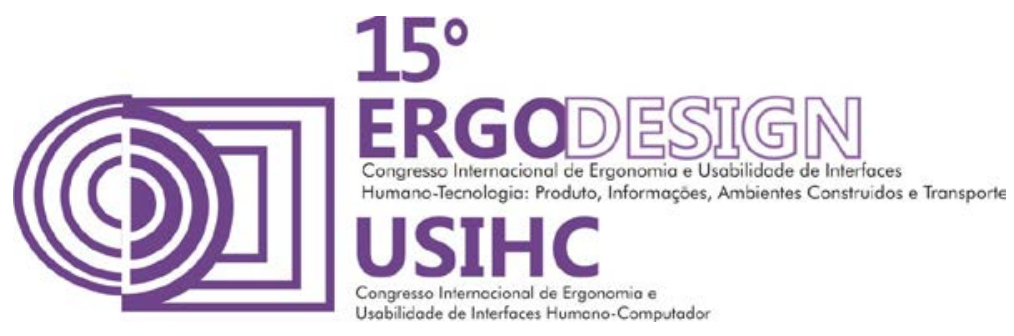

\section{O SENTIDO TÁTIL E APRENDIZAGEM DE PESSOAS CEGAS OU BAIXA VISÃO}

A comunicação e a educação estruturam-se a partir de códigos de linguagem compartilhados pelos sujeitos envolvidos no processo educativo e comunicacional. No universo das pessoas com baixa visão, com deficiências visuais ou cegas é por meio do toque e do sentido tátil que ocorre a percepção e a interpretação de mundo.

Diderot, já em 1749 em sua obra A Carta Sobre os Cegos, dedicou-se a reflexão sobre a relação entre visão, tato e aquisição do conhecimento. De acordo com Adell (2010, p. 35) a intenção de Diderot foi descrever, compreender e interpretar os fenômenos que se apresentam à visão e à falta dela, para desta forma conceber como se dá a contribuição dos sentidos para a aquisição do conhecimento e as relações de intercâmbio entre eles e ainda definir qual o lugar que a experiência ocupa na vinculação que existe entre os sentidos e o conhecimento. Para Diderot, a cegueira deixa de ter um interesse pela mera distinção de figuras e passa a ter seu foco principal em como uma pessoa cega pensa, sente e adquire conhecimento do mundo exterior. De acordo com Adell (2010, p. 46) Diderot constata a superioridade do cego em numerosos domínios tais como nas suas definições e conceitos, bem como com relação à sua memória para sons. Várias vezes Diderot reconhece que "o auxílio que nossos sentidos se prestam mutuamente os impede de aperfeiçoar-se", e uma conclusão a qual chega é que o fato de possuirmos múltiplos sentidos não nos garante uma percepção mais apurada e aguçada. O sociólogo Richard Sennett (CPF Cultura, web), ao discutir a noção de artesania (embora esteja mais interessado em discutir habilidades manuais em termos de maestria) também busca compreender qual é a sintonia entre a mão e a mente.

Ao abordar o sistema tátil de crianças cegas ou de crianças com baixa visão Lima e Silva (2000) consideram que poucos pesquisadores interessam-se por questões relacionadas ao sistema tátil no processo de aprendizagem e destacam a relevância dos estudos de Heller; os autores resumem algumas indagações levantadas sobre a relação entre o sistema tátil e visual e, adicionam suas próprias indagações: nós pensamos sobre o mundo em termos de imagens? A modalidade pela qual obtemos esta informação tem importância? Será que as pessoas cegas imaginam os objetos da mesma forma que nós, videntes, o fazemos? Será que entendem o espaço da mesma forma que o resto de nós? As pessoas cegas têm imagens? As imagens dos cegos são como as dos videntes? Quais são as implicações da falta de experiência visual para as imagens? As pessoas cegas percebem objetos e relações espaciais indefinidas de modo deficiente, porque podem faltar-lhes imagens mentais? Qual a natureza de seu imaginário? As imagens mentais são necessárias para alguns tipos de compreensão espacial? A essas perguntas Lima e Silva (Ibid.) acrescentam: como fazem ou são as representações mentais de pessoas cegas, produzidas a partir de objetos descritos por pessoas não-cegas, uma vez que estas, ao descreverem algo, usam de representações próprias de quem está vendo? Como são as representações mentais de "objetos" amorfos (chuva, por exemplo) feitas pelos cegos? Que processos são usados para a compensação do limite imposto pela falta parcial ou total da visão?

Paralelamente a estas indagações, os autores destacam a relevância que o sentido 


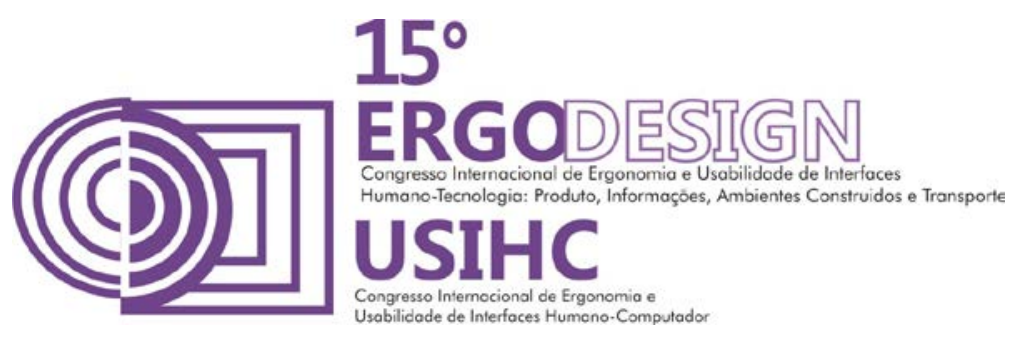

as mãos e o tato para estas pessoas e apontam a existência de uma lacuna de pesquisa sobre este seja no sentido de produção de conhecimento novo, ou seja pelo virtual uso dele para o desenvolvimento de tecnologia apropriada às necessidades desses indivíduos (Lima e Silva, 2000, web). Apoiados em estudos de sua própria autoria e me investigações conduzidos por Lederman \& Klatzky (1987), Lima e Silva (2000) consideram que o tato é hábil no reconhecimento de padrões 3D e, adicionalmente, oferece informações que não podem ser decodificadas pela visão como temperatura, textura e grau de lisura ou aspereza.

Grifin e Gerber (1996, web) defendem que a modalidade tátil vai além do mero sentido do tato e que este é amplamente confiável: esta modalidade fornece informações a respeito do ambiente, menos refinadas que as fornecidas pela visão. As informações obtidas por meio do tato têm de ser adquiridas sistematicamente, e reguladas de acordo com o desenvolvimento, para que os estímulos ambientais sejam significativos. Para os autores a ausência da modalidade visual requer a exploração do pleno desenvolvimento tátil e, de acordo com eles, a primeira fase do desenvolvimento tátil é a consciência das qualidades táteis dos objetos. $O$ sentido do tato começa com a atenção prestada a texturas, temperaturas, superfícies vibráteis e diferentes consistências. Pelo movimento das mãos, as crianças cegas se dão conta das texturas, da presença de materiais, e das inconsistências das substâncias. Também, através do movimento das mãos, as crianças cegas podem apreender os contornos, tamanhos e pesos. Essas informações são recebidas sucessivamente, passando dos movimentos manuais grossos à exploração mais detalhada dos objetos.

Em síntese, Diderot está interessado em entender os mecanismos de aquisição de conhecimento de pessoas cegas a partir do mergulho em suas histórias, e compreender como ocorre o apuro dos outros sentidos para superar a ausência da visão. Sennett quer entender qual é a sintonia entre a mão e a mente. Já para Lima e Silva o problema central é o sistema tátil no processo de aprendizagem e como ocorrem as representações mentais de pessoas cegas, inclusive de conceitos abstratos. Enquanto isso Griffin e Gerber trazem considerações relevantes para o foco deste artigo na medida em que relacionam o desenvolvimento tátil de pessoas cegas com o processo de consicência das qualidades táteis dos objetos.

\section{A TECNOLOGIA 3D E SUA POTENCIALIDADES COMO FERRAMENTA DE VISUALIZAÇÃO E COMUNICAÇÃO NO PROCESSO EDUCATIVO.}

\subsection{O Grupo Homero 3D}

O Grupo Homero 3D foi criado no dia 07 de novembro de 2014 com a intenção de fomentar pesquisas teóricas e práticas com foco na impressão 3D e seu potencial como recurso facilitador de pessoas com deficiência visual. O grupo conta com sete participantes associados, como alunos ou professores, ao Programa de Mestrado em Design, ao Departamento de Design da Univille e ao Instituto Caranguejo de Educação Ambiental (com foco na educação 




ambiental para o público infanto-juvenil e parceiro desta proposta). O nome Homero pretende homenagear o poeta grego autor de lliada e Odisséia. Embora sua existência não seja confirmada estudos sobre sua obra registram que ele era cego e, na análise de Giambattista Vico apud Malta (2012), tal fato pode ter contribuído com o desempenho de sua memória já que sua poesia está associada a tradição oral.

Além de encontros para discussão e experiências de impressão 3D, uma das estratégias de investigação utilizadas baseia-se na criação um espaço virtual para reunir experiências publicadas com foco na impressão 3D voltadas para deficiência visual. Entre as experiências documentadas destacamos: Touchable Memories: Impressora 3D reproduz fotos antigas para deficientes visuais relembrarem o passado; NASA Imprime em 3D imagens do universo para que pessoas cegas possam compreende-lo; e, Finger Reader possibilita leitura para cegos. Estas experiências foram detalhadas no intuito de possibilitar a discussão sobre caminhos futuros do grupo.

\begin{tabular}{|c|c|c|}
\hline Experiência & Descrição & Imagens \\
\hline $\begin{array}{l}\text { Touchable Memories: } \\
\text { Impressora 3D reproduz } \\
\text { fotos antigas para } \\
\text { deficientes visuais } \\
\text { relembrarem o passado }\end{array}$ & $\begin{array}{l}\text { Memórias Tocáveis (ou Touchable } \\
\text { Memories) é um experimento voltada } \\
\text { para pessoas que perderam a visão e } \\
\text { tem a intenção de ajuda-las a reviver } \\
\text { as memórias a partir da impressão 3D. } \\
\text { Foram convidadas } 5 \text { pessoas que } \\
\text { indicaram fotografias de momentos } \\
\text { memoráveis que serviram com } \\
\text { referência para a impressão. }\end{array}$ & \\
\hline $\begin{array}{l}\text { NASA Imprime em } \\
\text { 3D imagens do } \\
\text { universo para que } \\
\text { pessoas cegas } \\
\text { possam compreende- } \\
\text { lo }\end{array}$ & $\begin{array}{l}\text { Carol Christian e Antonella Nota } \\
\text { membros do Instituto da Ciência } \\
\text { Telescópica Espacial conduzem um } \\
\text { projeto com a intenção de ajudar } \\
\text { pessoas cegas a enxergar o cosmo } \\
\text { com as mãos. O método usado } \\
\text { consiste em traduzir imagens } \\
\text { registrados pelo telescópio espacial } \\
\text { Huble para imagens impressas em 3D } \\
\text { possibilitando que pessoas cegas } \\
\text { possam senti-las com o tato e elaborar } \\
\text { uma ideia do formato do espaço. }\end{array}$ & \\
\hline
\end{tabular}



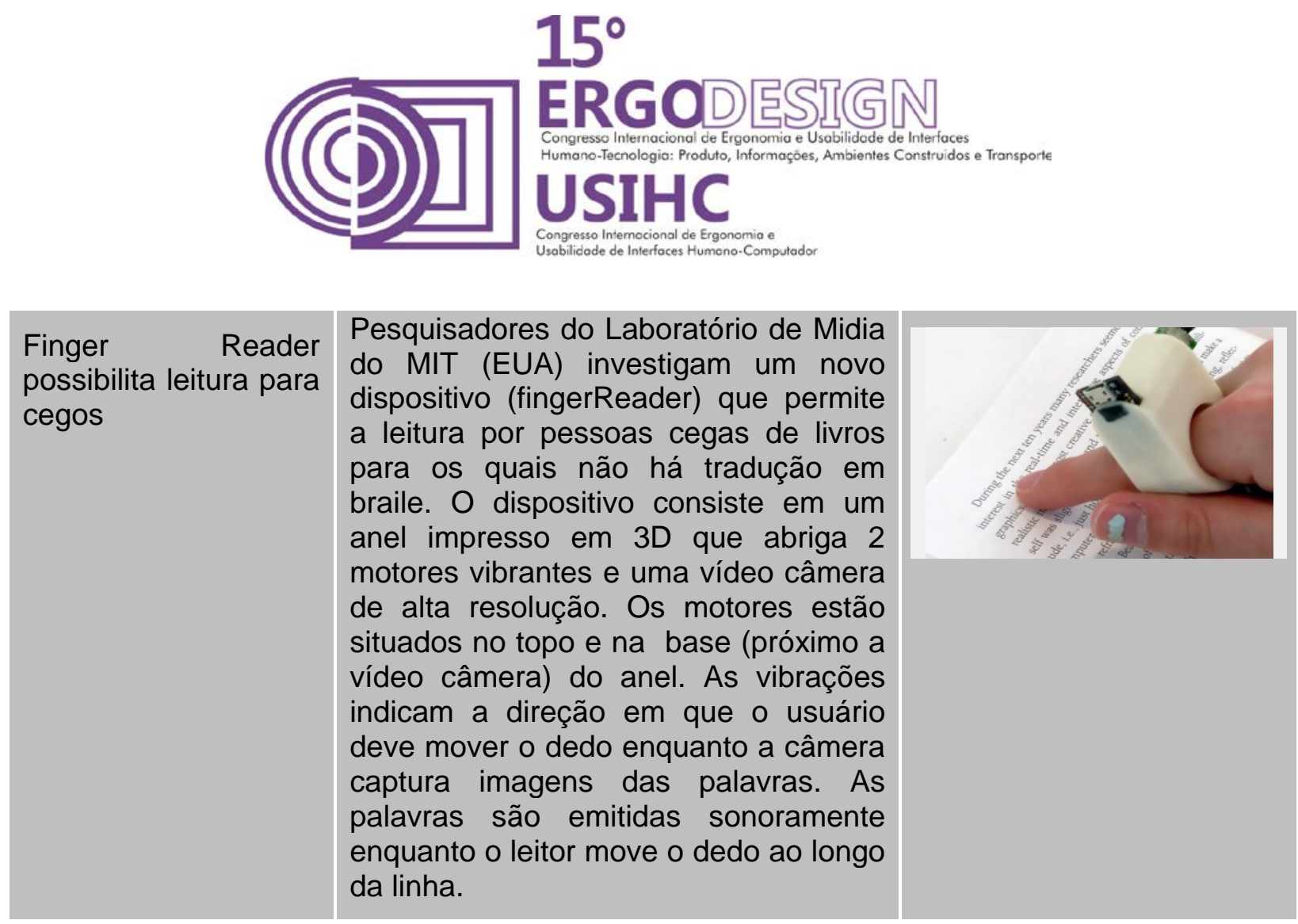

Figura 1: A impressão 3D e produtos para pessoas de baixa visão ou cegas

Fonte: NEWMAN (Web), NASA is 3D Printing Hubble Images So Blind People Can See Outer Space (Web). Touchable Memories: Impressora 3D reproduz fotos antigas para deficientes visuais relembrarem o passado (web)

Ao longo deste levantamento notou-se que para além da alta tecnologia, o desenvolvimento de artefatos de suporte cognitivo à pessoas com deficiência visual vem adquirindo espaço em editais de pesquisa e tem se tornado tema central de grupos e laboratórios de pesquisa. Uma destas iniciativas esta sendo conduzida sob a coordenação da Professora Karina Carvalho Mancini que explora possibilidades tridimensionais e o sentido tátil para facilitar a aprendizagem sobre organelas, estruturas celulares e outros conceitos de citologia por pessoas com deficiência visual. Dentre estes estudos destaca-se a monografia "A célula ao alcance das mãos: Construindo Modelos Didáticos para o Ensino de Citologia com Deficientes Visuais", desenvolvida pela Andressa Antônio de Oliveira aluna do curso de licenciatura em Ciências Biológicas do Centro Universitário Norte do Espírito Santo. 

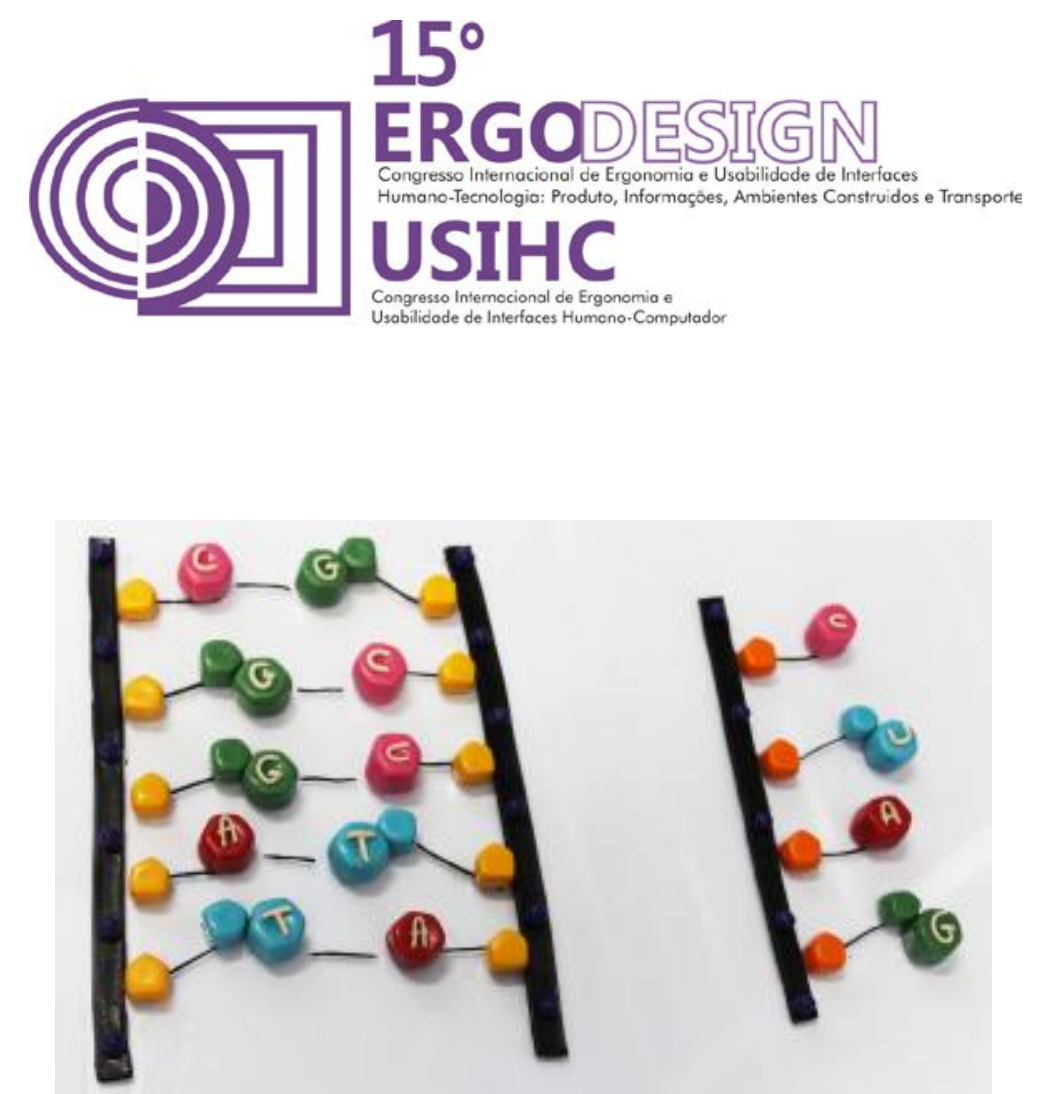

Figura 2: Modelo para facilitar a aprendizagem de conceitos científicos para pessoas de baixa visão ou cegas

Fonte: Universidade Federal do Espírito Santo (web)

Salienta-se que esta proposta é uma das soluções desenvolvidas e que há modelos de outros conceitos, com objetivos similares, em construção.

\section{CONDIDERAÇÕES FINAIS E CONCLUSÃO}

O gesto manual, a mão, o sentito tátil e o toque possibilitam a ampliação do 'olhar', a 'leitura' e a interpretação de informações para todos nós. Mas, para pessoas de baixa visão, ou cegas, estes recursos se tornam imprescindíveis e o tato é o principal sentido de percepção.

Hoje a inclusão de pessoas com deficiências adquiriu maior relevância em várias dimensões do nosso cotidiano (legislação, empregabilidade, acessibilidade, habitação, consumo, educação, etc) o que, inevitavelmente, repercutirá na intensificação de pesquisas e na geração de conhecimento com este enfoque. É neste cenário, e com estas considerações em mente que o grupo Homero 3D se movimentou.

As leituras referentes a linguagem, tato e aprendizagem com foco em pessoas cegas ou de baixa visão evidenciaram que, embora a preocupação em compreender o sentido do tato no processo de aprendizagem remeta a estudos iniciados no século XVIII, ainda há muitas lacunas e questões a serem respondidas.

Esse contexto, entretanto, não deve limitar o avanço de experiências similares aquelas propostas pelo grupo Homero 3D. O levantamento efetuado confirma que a impressão 3D está em franca expansão e tem grande potencial de contribuir para atividades comunicacionais e educacionais de pessoas cegas e de baixa visão no que se refere a: (1) a 'materialização' de memória de pessoas que perderam a visão ao longo da vida como no caso do projeto Touchable Memories; (2) a configuração de conceitos abstratos possibilitando esquemas visuais que podem ser 'olhados' com as mãos e o tato como no caso das impressões 3D do 


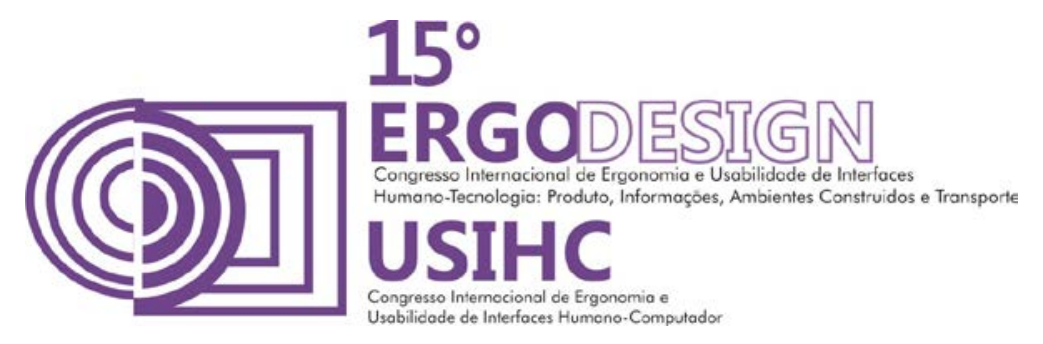

universo efetuados pela NASA, (3) a conversão da impressão textual em sinais sonoros como no caso do FingerReader, e, (4) a ferramentas de auxílio para aprendizagem de conceitos científicos em um movimento similar com o que vem sendo feito pela coordenação da Professora Karina Carvalho Mancini.

\section{REFERÊNCIAS BIBLIOGRÁFICAS}

ADELL, Edna Amaral De Andrade. A questão de Molyneux em Diderot. Dissertação de Mestrado. São Paulo : USP. 2010.

Braille tape by kukil han from korea. Disponível em: http://www.designboom.com/project/braille-tape/. Acesso em: 7 nov. 2014.

CPFL Cultura. Fronteiras do pensamento e instituto cpfl/ cultura: entrevista exclusiva com richard sennett. Disponível em http://www.cpflcultura.com.br/wp/2013/12/18/fronteiras-do-pensamento-einstituto-cpfl-cultura-entrevista-exclusiva-com-richard-sennett/. Acesso em: 7 jan. 2015.

DUARTE, Henrique. Descubra como surgiu a impressora 3D. Disponível em http://www.techtudo.com.br/dicas-e-tutoriais/noticia/2014/04/descubra-como-surgiu-impressora-3d.html. Acesso em: 7 jan. 2015.

ESTES, Adam Clark. NASA Is 3D Printing Hubble Images So Blind People Can See Outer Space. Disponível em http://www.gizmodo.in/.../NASA-Is-3D.../articleshow/28608409.cms. Acesso em: 07 jan 2015.

GRIFIN, Harold; GERBER, Paul. Desenvolvimento tátil e suas implicações na educação de crianças cegas. Disponível em ibc.gov.br. Acesso em: 07 jan 2015.

LIMA; Francisco José de Lima; SILVA, José Aparecido da Silva. Algumas considerações a respeito do sistema tátil de crianças cegas ou de visão subnormal. Disponível em FJ de Lima, JA da Silva - 2000 - ibc.gov.br. Acesso, 05 jan. 2015.

London Museum Uses Israeli Tech To Create 3d Printed Statues Of Visitors. Disponível em Http://Www.Shalomlife.Com/Business/20935/London-Museum-Uses-Israeli-Tech-To-Create-3d-PrintedStatues-Of-Visitors/. Acesso em: 03 jan. 2015

MAITA, André. A Morte e a Vida de Homero: três visões do poeta grego publicadas no século XVIII . REVISTA USP・São Paulo・n. 94・p. 166-175• Junho/Julho/Agosto 2012.

NASA is 3D Printing Hubble Images So Blind People Can See Outer Space. Disponível em http://www.gizmodo.in/science/NASA-Is-3D-Printing-Hubble-Images-So-Blind-People-Can-See-OuterSpace/articleshow/28608409.cms. Acesso em: 7 nov. 2014.

NEWMAN, John. FingerReader Offers Reading for the Blind in 3D Printing Applications, Prototypes. July 9, 2014. Acesso em: 7 nov. 2014. 


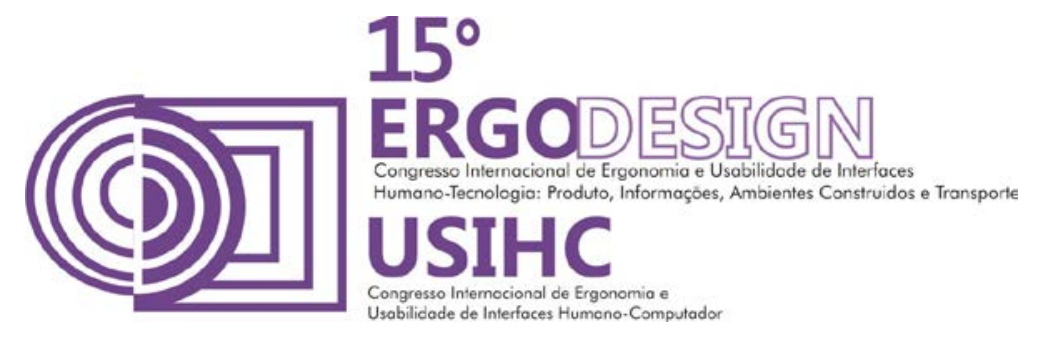

Touchable Memories: Impressora 3D reproduz fotos antigas para deficientes visuais relembrarem o passado. Disponível em http://www.hypeness.com.br/2014/10/impressora-3d-reproduz-fotos-antigaspara-deficientes-visuais-relembrarem-o-passado/. Acesso em: 7 nov. 2014.

The DrawBraille Mobile Phone. Disponível em http://inhabitat.com/the-drawbraille-mobile-phone-byshikun-sun-is-a-super-smartphone-for-the-blind/ Acesso em: 7 nov. 2014.

UNIVERSIDADE FEDERAL DO ESPÍRITO SANTO. Trabalho facilita o ensino de citologia para deficientes visuais. Disponível em: http://portal.ufes.br/conteudo/trabalho-facilita-o-ensino-de-citologiapara-deficientes-visuais. Acesso em: 2 fev. 2015. 